\title{
Women, capitals and fishing lives: exploring gendered dynamics in the Llŷn Peninsula small-scale fishery (Wales, UK)
}

\author{
Madeleine Gustavsson ${ }^{1}$ (D) Mark Riley $^{2}$ \\ Received: 21 April 2018 / Accepted: 17 August 2018 / Published online: 30 August 2018 \\ (C) The Author(s) 2018
}

\begin{abstract}
Many researchers have noted the under-representation of women within fisheries' policy and academic research. Fishing menin commonly being the registered fisher and most often performing the visible tasks of fishing - have been the primary focus of fishing statistics as well as the subject of more in-depth qualitative analyses. Recent work focusing on fishing men in small-scale fisheries has drawn on Bourdieusian notions of capital(s) to examine how capital is accrued and exchanged as fishers seek to (re)position within their fishing network. This paper develops this framework by examining the role and position(s) of women in the development and transformation of capital(s). Drawing on in-depth qualitative research with fishing families in a case study of the Llŷn Peninsula, Wales (UK), the paper explores how the gendering of particular fishing places and practices, as well as discursive downplaying of women's actual involvement in fishing, limit the extent to which women are able to accrue and exhibit capital. We find that women's everyday, often 'hidden', activities are central to facilitating capital development and circulation within the fishing family businesses. Whilst we note that fishing remains a masculinised activity — particularly those aspects performed at sea - we examine how the position of women in the industry has changed over time and how this might have significant ramifications for the future of fishing in this area.
\end{abstract}

Keywords Symbolic capital · Gender capital · Emotional capital · Llŷn Peninsula, Wales (UK) · Fishing families

\section{Introduction}

Many researchers have suggested that women are underrepresented in fishing (Kleiber et al. 2015). In an attempt to fill this research gap, scholars have sought to make women's roles more visible within the sector by recording the multifarious tasks that women do undertake, both formally and informally (see Nadel-Klein and Davis 1988; Frangoudes 2013). More broadly, and informed by feminist scholarship, others

This paper belongs to Topical Collection (En)Gendering Change in Small-scale Fisheries and Fishing Communities in a Globalized World

Madeleine Gustavsson

m.c.gustavsson@exeter.ac.uk

Mark Riley

mark.riley@liverpool.ac.uk

1 European Centre for Environment and Human Health, University of Exeter Medical School, Knowledge Spa, Royal Cornwall Hospital, Truro, Cornwall TR1 3HD, UK

2 Department of Geography and Planning, University of Liverpool, 413, Roxby Building, Liverpool L69 7ZT, UK have recently sought to unpack the gendered nature of power relations within fishing which might contribute to these gender biases (Gerrard 2008; Porter 2012). Gaps remain, however, in our understandings of the 'cultures, values and meanings underpinning gender identities' (Little and Panelli 2003, p. 283 ) and how these variously shape women's position(s) within the fishing industry, family and community in varying geographical contexts. In paying attention to this void, this paper focuses on the gendering of everyday life in the fishery, including fishing families and communities, and utilises Pierre Bourdieu's thinking around capital as a way of exploring how value and meaning are developed through, and associated with, symbols (be they activities, knowledge or dispositions) - or cultural capital — which may be 'convertible into economic and social benefits' (Illouz 1997, p. 41). Previous studies have utilised Bourdieu's ideas of capitals in developing the concept of the 'good fisher', which considers how individuals' social positions and status are shaped by the extent to which they adhere to the shared standards and values of the fishing culture (Gustavsson et al. 2017). To date, however, the value of this approach has primarily been realised through discussions of fishing men. In large part, this is due to the methodological issue of men's fishing work and the associated 
development, display and (re)use of capital(s) being more easily observable. In the following paper, we wish to address this myopic tendency and to examine the extent to which women are able to accrue and exchange capital(s) within the context of the fishing occupation, family and community. In particular, the paper will examine the 'gendered dispositions' (McCall 1992) of capital(s) in fishing to consider the evolving role(s) of women within the development and transfer of capitals within small-scale fishing family enterprises. Following an outline of this conceptual framing and the associated methodological approach, the paper will move on to examine women's multiple positions and subjection positions within fishing, families and communities in the study area.

\section{Conceptualising the study}

In reviewing the literature on gender within rural contexts, Little and Panelli (2003) note a general move towards viewing gender as a process of social construction in time and place, but note how this trend has been more pronounced in the discussion of agricultural than in fishing (Skaptadottir (1996); Yodanis (2000); Waitt and Haritig (2005) and Gerrard (2013) are important exceptions). ${ }^{1}$ A recent development within the literature on fishing has been the incorporation of Bourdieu's ideas of capital-which have helped move beyond a focus on economic capital (material goods), to also note how social capital (emanating from, and reaffirmed by, social contacts) and cultural capital (knowledge, skills and dispositions which may be gained by socialisation and education) are developed and used to (re)position individuals within the fishing occupation, family and community (Gustavsson et al. 2017). This framing also examines how symbolic capital - the form that these other types may take on when they are 'perceived and recognised as legitimate' (Bourdieu 1986, p. 17) within a particular field - is central to defining which forms of capital (as well as how they are used) are seen as legitimate and enable individuals to position, and be positioned, within society - that is, they help define the 'rules of the game'. The work adopting this framework has added a more detailed picture of fishing lives (Gustavsson and Riley 2018), but in order to develop a more nuanced understanding of gender within small-scale fishing, we draw upon the insights of feminist scholars who have critiqued and appropriated Bourdieu's work. Fundamental to their critiques of Bourdieu is an assumption, read into his original writing, of a level of gender fixity across times and cultures and a failure to

\footnotetext{
${ }^{1}$ Although there are very distinct differences between the fishing industry and agriculture, agriculture is a useful comparator given the primary importance of patriarchal inheritance, the blurring of the boundaries between home/work and work/non-work and the centrality of familial relations in the continuation of smaller-scale operators. See Gustavsson et al. (2017) for a discussion of these similarities and differences.
}

recognise that different fields may draw out different ways of doing gender and, accordingly, such gender performances may be both multiple and evolve in relation to different contexts (Chambers 2005). The subsequent gendering of Bourdieu's capitals has examined the power relations which are at play in the (re)production and transformation of capitals (Huppatz 2009) and a recognition that rather than being repositories of capital (cf. Bourdieu 1984), women may develop their own capital-accumulation strategies (McNay 2000). For Reay (2005), this involves recognition of 'emotional capital'- a species of capital not noted by Bourdieu, which she sees as 'emotionally valued assets and skills, love and affection, expenditure of time, attention, care and concern'. This type of capital is inherent in the multifarious 'caring' roles that are most often undertaken by women-such as supporting children and partners and sustaining relationships within and beyond the family. As Reay (2005) notes, this capital tends to be gendered, but is not insignificant as a result of its ability to be transferred into social and/or economic capital.

Huppatz (2009) extends Bourdieu's notion of 'embodied cultural capital' (that is, skills and dispositions) to include gendered capital and draw useful distinction between femaleness and femininity 'female capital and male capital relate to the gender advantage that is derived from being perceived to have a female or male body, whereas feminine capital and masculine capital relate to the gender advantage that is derived from a disposition or skill set, or from simply being hailed as feminine or masculine'. From their observation, we are able to make sense of how women and men can sometimes embody different capitals in the same occupational sectors (Huppatz and Goodwin 2013). Taking the perspective that everyday practices and spaces can become gendered, we can, in turn, recognise how these gender distinctions structure individuals' access, development and embodiment of capitals in the fishery. Alongside this, if we recognise that gender is subject to ongoing socio-cultural negotiation - both at societal and individual levels - we can see how gender(ed) positions are open to reworking and that women in fishing may be agents of change.

\section{Methodological approach and research setting}

The paper draws on Gustavsson's (2016) doctoral research of the socio-cultural contexts of fishers and fishing lives on the Llŷn Peninsula, North Wales, UK (see Fig. 1) (also see Gustavsson et al. 2017; Gustavsson and Riley 2018). The wider study sought to understand what it means to be a fisher and to live in a fishing family. The Llŷn Peninsula is part of the municipality of Gwynedd - a remote and rural part of Northwest Wales (see Fig. 1) which has a population of less than 30,000 people (Gwynedd Council 2014). Llŷn Peninsula 


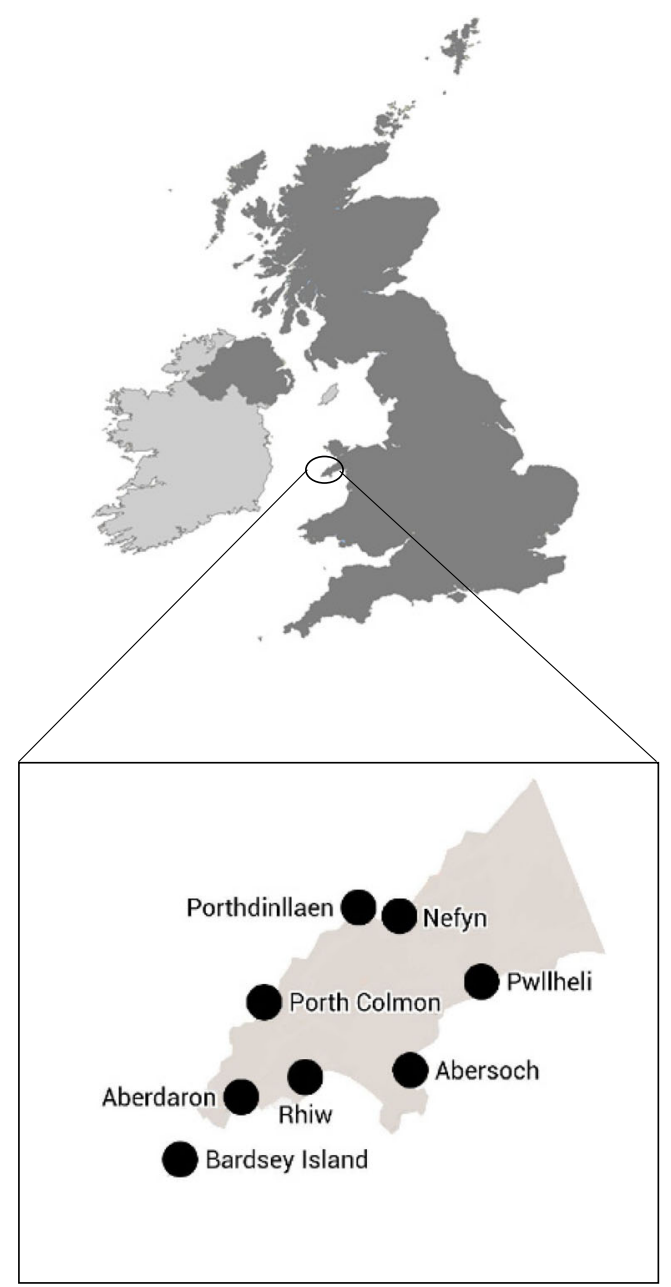

Fig. 1 Map of the Llŷn Peninsula, North Wales, UK

is part of what is often called the 'Welsh heartland' (see Jones and Fowler 2007), and over $80 \%$ of the population speaks Welsh as their first language - and almost all of the fishers spoke Welsh in their everyday life. As one respondent explained:

99 percent of the fishermen here are all Welsh. [...] We are all Welsh speakers. We are all from the area. That is part of the community. [...] I think $70-80 \%$ of the people in this area are Welsh. So I think it's the most Welsh part of Wales. [...] The terminology that [we fishers use] is all in Welsh. [...] I struggle to use English terminology because [...] you just learn to use Welsh terms for weather, for lobster gear, the boat. Sea conditions... (Man 22).

Although the participants interviewed primarily spoke Welsh as a first language, the interviews were conducted in English. As highlighted in the extract above, this risked losing some of the nuance of language and culture but, we argue, this also provided opportunities to unpack some of its meaning. There was a strong sense of history, national identity and place associated with being Welsh amongst those spoken to. The study areas have struggled with outmigration of 'skilled' and 'educated' young people to other parts of the UK, and, at the same time, there was in-migration of older people - mainly retirees who wanted to settle in the coastal landscape of the Llŷn (Gwynned Council n.d.). Respondents reported that those who stayed have struggled to buy homes in the subsequently elevated housing market. As a consequence, although most lived in proximity to their fishing areas, some younger fishers lived further away (approx. $20 \mathrm{~min}$ drive) where housing was cheaper.

The Llŷn Peninsula is primarily a small-scale fishery ( $<10 \mathrm{~m}$ boats), and fishers fish for (non-quota) ${ }^{2}$ lobster, crab and scallop. Fishers on the Llŷn Peninsula fish either from fishing coves and launch their boats every time they go out, or use boats lying on moorings, accessible by small dinghies. In 2016, Wales had a high proportion (compared to other areas of the $\mathrm{UK}^{3}$ ) of small-scale fishing with 419 out of 451 boats under $10 \mathrm{~m}$ (Marine Management Organisation 2017). Wales has a relatively high percentage of part-time fishers (42\%), and the sample interviewed had a similar distribution (Marine Management Organisation 2017). An economic study conducted in 2012 found that the average annual wage for full-time small-scale lobster and crab fishers was $£ 17,062$ (Cambiè et al. 2015, p. 17). ${ }^{4}$ A report published by the European Parliament (Frangoudes 2013) has found that almost $14 \%$ of those who work in fisheries, processing and aquaculture in the UK are women, but more detailed information, which is not available, is needed to understand this sector from a gender perspective. Apart from fishing, tourism, farming, health care and local schools were the main sources of employment in the area. In the study area, women were most often employed in health care, school and seasonal tourist employments.

The study conducted 48 interviews with 35 participants from fishing families linked to 16 different fishing boats with the majority interviewed on more than one occasion. Qualitative semi-structured individual, couple and repeat

\footnotetext{
${ }^{2}$ Whilst women in other places, such as Munk-Madsen's (1996) research in North Norway, found that state-led quota policies have undermined women's direct ownership of 'fishing capital' (specifically quotas), the case of Llŷn Peninsula is a non-quota fishery with differing consequences for women's ownership of economic capital. Many women spoken to highlight that the fishing business was a partnership in which they had some level of ownership, although more research is needed to understand the specifics of these partnerships.

${ }^{3}$ There was a total of 6195 fishing boats (and 11,757 registered fishers) in the UK: England (under ten, 2569; and over ten, 529), Scotland (under ten, 1456; and over ten, 575) and Northern Ireland (under ten, 202; and over ten, 149). This makes Wales the heartland of small-scale fishing in the UK (Marine Management Organisation 2017).

${ }^{4}$ This is below the media annual wage for this area (West Wales and the Valleys) of $£ 26,270$ (National statistics for Wales 2013).
} 
interviews were conducted in 2014 and 2015 and, where possible, all members of fishing families were interviewed, including 6 women (W); 20 men (M); 7 sons (S) and 2 daughters (D). Where permissible, participant observation was used to triangulate what was said in the interviews with what participants do. Initial contacts were established with two local fisheries committees with members providing a first wave of respondents, with chain-referral sampling used to locate subsequent waves. Whilst mainly men were identified through this approach, the study sought to interview family members who were contacted by asking men to refer us to their partner and children. Although this approach meant that men could potentially act as gatekeepers to the voices of women, this was counteracted by asking the women interviewed to also refer others in the area. Qualitative and semi-structured interviews were used to gain an understanding of the gendering of fishing activities, identities and networks. The participants chose the interview locations - often conducted in the homes of fishing families - and interview lasted for between $45 \mathrm{~min}$ to $2 \mathrm{~h}$, were recorded and transcribed verbatim. Each transcript was read through several times and coded manually following the framework set out by Reismann (2008) for thematic narrative analysis. The paper reports on the subsequent themes which emerged from the analysis, specifically relating to women's knowledge, roles and identities, and these are represented in the following interview extracts and discussion.

\section{'I don't class myself as a fisherman': women's bodies, role(s) and fishing capitals}

Interviews revealed that one of the most overt ways in which the fishing occupation became gendered is through the positioning of women's bodies as unable to fish:

I am not against women doing anything at all. But there is no way I could lift those things [e.g., lobster pots]. Because [fishing men are] really strong. [...] I just don't think women could do it (W-9 [Age, 60]).

The interviews were replete with similar statements which highlight how, in the everyday language of the study area, the fisher is a masculine subject. Rarely, as the extracts above show, was this discourse challenged in interviews by either men or women. Instead, most women - like woman 9-had internalised the notion of 'it is a man's job' (W-5). Commonly, the reasons given for women's non-participation in fishing centred on the idea that 'women are a lot weaker than men' (M-8). Such notions highlight how, both advertently and inadvertently, physically strong bodies-constructed as masculine - work, as Power $(2005$, p. 89$)$ has noted for fishing in Newfoundland, Canada, 'to exclude women from fishing and to legitimise such exclusion'. Using the idea of capital, however, observations like these highlight the fishing field is, ostensibly, one that prizes bodily capital (it becomes legitimated symbolic capital) - that is, 'male capital'. This discursive subjugation of women's roles was underpinned by, and intertwined with, more literal, spatial and material elements:

Interviewer: 'You were saying before that you have only been on the boat a few times...'

Women: 'Yeah... Oh no, I have no interest. Really. No. It is... the smell of the boat, the smell of diesel and fish" (W-5 [Age, 60]).

Woman: 'I have helped to fetch things for you...' Man: 'Ring people up...'

Woman: 'Or take the fish everywhere [Laugh]. You don't think about it, you just do it automatic don't you" (W-21 and M-12 [Age, both 60]).

Two elements can be drawn out from these extracts for our wider understandings of gender relations within fishing - how bodies are used and where bodies are used. The fishing boat, in this context, is a key site of capital display and accumulation. As Gustavsson et al. (2017) and Gustavsson and Riley (2018) have shown, the boat is an important site of masculine performance as well as capital display. At one level, this relates to the notion of physical ability referred to above, but at another level includes technical competence - something seen as a key aspect of the embodied cultural capital that fishing men need to demonstrate to elevate their 'good fisher' standing in the community. As woman 15 suggested, 'I will just be helping out with taking the crab and lobsters out the pot and things and let him drive the boat'. Such examples illustrate that even when women $d o$ go on the boat, they exclude themselves (both discursively and literally) from being in charge of the boat and serve to reinforce the masculine subjectivities of their fishing partner and to develop fishing men's capital. The term 'fisherman' becomes not only labelled in relation to bodily capabilities, as noted earlier, but through the embodied cultural capital (skill)—or 'masculine capital' (Huppatz 2009) — that these fishers display. As woman 21's extract highlights, women are clearly involved in the work of fishing, but because they do not demonstrate the embodied cultural capital in the right spaces, for example the boat, their activities do not develop symbolic value in the same way, and they do not take on the label of 'fisherman'. These observations echo those of MunkMadsen (2000) who suggests that women who fish together with their husbands voluntarily submit themselves in the context of boat operation to elevate the masculine identity and symbolic value of their fishing partner. Furthermore, women's submission is simultaneously and indirectly a performance of the localised form of femininity as '[t]he vessel is an arena 
which is devoid of positive symbols of femininity' (MunkMadsen 2000, p. 339). Hinted at within the interview exchange with woman 21 and man 12, however, is that far from being inactive, women play a key role in fishing through others roles and through the deployment of other types of capital - a theme to which the paper now turns.

\section{Women's position in fishing families and emotional capital}

Whilst the previous section highlighted both the enforced and seemingly more voluntary exclusion of women from some of the sites of fishing, and hence, some of the key sites of capital accumulation, the interviews also offered insights into the more routinized tasks that the women undertook in other spatial contexts:

If the weather is nice he fishes. So [...] what I do is that I just carry on. I look after the kids and do everything and we just carry on without [him]. So we just plan stuff. And if he is with us he is with us and if he is not he is not. So a lot of the time he is not cause he is fishing (W-17 [Age, 45]).

At one level, the observations here echo the common finding in gender research, and on fishing specifically (see Zhao et al. 2013), that women perform 'invisible', 'unpaid' and 'unrecognised' roles_-something especially pronounced in fishing given the distinct material separation between spaces of home (commonly coded as a space for women) and spaces of work (commonly coded as a space for men). At a second level, we see a simultaneous discursive downgrading of their own work and elevation of that of their male fishing partners. Woman 17's account, for example, serves to present her husband as the absent 'hero' and at the same time frame her own labour and skills of motherhood and homemaking, relationally as 'everything else'. Whilst the status of this 'everything else' is downgraded in relation to that of fishing (specifically the activities on boats), the everyday life of fishing families onshore is a context in which women demonstrate their own capital accumulation. Other authors have noted that women support the wellbeing and health of their male-fishing partners through their emotional labour (Britton 2012; Kilpatrick et al. 2015). The placing of this emotional capital is important. It is not simply that they 'support' their husband, but that they mobilise their own emotional and cultural capital (as good mothers) into a set of practices (of the family) which allow their husbands the freedom to undertake their fishing relatively freely. In essence, it provides a competitive economic advantage for the fisher at it allows them the freedom to go out fishing when the right conditions are available.
Gustavsson and Riley's (2018) recent analysis has highlighted the importance of entry points (or social contexts) into the fishery which offer differing social relations and structure the access and accumulation processes relating to fishing capitals. Within our sample, the women involved in fishing had come to the industry via partnership or marriage. Whilst we do not claim this to be the only, or most common, route into the industry, their experiences offer an insight into how the process of socialisation in fishing may be gendered. The following extract comes from an interview with a fisher whose wife 'married into' fishing:

My wife is fortunately from a farming background. Because she [...] knows that you have to work and that you can't sort of just have a day off or go on holiday or whatever. So when [the children] are off this week with half-term you are trying to take a few days off. But [...] with the weather dictating-especially in the winter-you gotta go fishing cause the [sea] days are very limited (M-10 [Age, 45]).

This example illustrates that whilst the fisher's wife was new to the industry and did not possess direct knowledge and associated capital, they were able to bring emotional capital from their allied experience of the family farm, whereby the persistence of the family business means that individuals, and women in particular, may involve 'self-sacrafice....in the name of the general family welfare' (Gersick et al. 1997, p. 3). For fishing women, direct experience of fishing was less common. The following extract comes from someone who had no experience of fishing prior to her marriage:

Man: 'It is taking part isn't it?'

Woman: 'Yeah, this is it.[...] You get involved and it is sort of hands on and then you ask 'what do you want me to do' and you just pick it up along the way' (M-14 and W-15 [Age, 45]).

And later on in the interview:

Interviewer: 'I was thinking the way you have learned to fish sounds quite similar?'

Man: 'Yeah. Except you have been ordered to do it'. Woman: 'Yes'.

Man: 'I have just been mad enough to do it'.

Woman: 'Yeah yeah. Labour of love' (M-14 and W-15

[Age, both 45]).

We see here that the process of learning to fish takes place much later in the lifecourse for women in fishing families. By its nature, this later socialisation offers comparatively little opportunity to develop their own forms of fishing capital, as 
their work is framed as 'labour of love' directed by, and through, the position of their male-fishing partner. Reay (2005) argues that although 'emotions within the family have traditionally been conceptualized as standing outside economic interpretations', the economy of emotion operates within families - and that it is often the responsibility of women. The extract above illustrates how for woman 14's, and many similar women, initial entry into fishing was not driven by a desire to fish, but also highlights how the occupation becomes indivisible from the wider emotional capital that women develop - which, in turn, supports the emotional and economic wellbeing of her fishing partner and family. The interviews revealed that this gendered distancing from the spaces of fishing was also tied to the 'patrilineal transfer of ecological and experiential knowledge' (Neis et al. 2013, p. 64):

Fishing is part of pretty much everybody's lives down here because you are so close to the sea. When you are youngsters you go fishing with a rod and reel off the rocks. From when we were about ten.[...] Everybody does it. It is just something to do on a weekend. And it is a good way to socialise with your mates (S-24 [Age, 20]).

For boys, 'playing' and 'socialising' around the seashore and around fishing sheds gave them access to the stories of male fishers and both direct and indirect learning of fishing skills. This more indirect secondary consequence of gendered positioning sat alongside the more conscious involving of their sons in the discussion of fishing activities. For several fishing men, this was reported as an 'investment in the future' (M-8), with an underlying expectation that these sons would become fishers themselves. Whilst a son's participation in fishing activities is seen as an investment for their entry into the fishery, daughters' participation in fishing activities are, by contrast, seen as 'help'. The research revealed that such gendering of women's early socialisation has knock-on consequences for the gendering of fishing practices, capitals, networks and spaces. However, interviews with fishing women highlighted how socialisation was not a passive process. Parents, implicitly and explicitly, attempted to make their mark on their children's future by encouraging or discouraging them from certain activities and life-paths. Whilst the earlier examples illustrated how more traditional gender(ed) pathways are perpetuated within fishing, other patterns have also started to emerge. Authors such as White (2015) and Power (2012) have noted that the tradition of fishing sons following into the industry is becoming less common, and our consideration of women's emotional capital, as an analytical approach, offers a nuance to this discussion. Reay (2005) notes that mothers' emotional capital may be engaged in 'awakening the consciousness' (after Bourdieu 1990) of children. The following extract exemplifies this:

Man: '[My son] doesn't want to be a fisherman'.

Woman: 'Yeah come and tell this lady about being a son of a fisherman'.

Man: 'Do you want to be a fisherman?'

Son: 'No'.

Interviewer: 'Why not?'

Woman: 'Tell her why not'.

Son: 'Back'.

Woman: 'Yeah, bad back'.

Son: 'Stress, eh...'

Interviewer: 'What do you want to do instead?'

Son: 'Anything else except that'.

Woman and man: '[Laugh]'.

Woman: 'Straight from the mouth. What do you want to do, maths teacher?'

Son: '[silence]'

Woman: 'Yeah, I think what it is, is that they know how hard it is'.

Man: 'It is as hard you want to make it'.

Woman: 'Yeah but you try to put rose colour spectacles.

But the reality of it is [that it is] hard, I don't know a harder job really. And then it is dangerous as well isn't it' (M-16, W-17 [Age, both 45] and S-34 [Age, 10]).

Highlighted in this extract is how the son of this family had been made aware of the 'stress' and hardness of the fishing occupation - something not aligning with the narrative presented by the fishing father throughout the interview. Such examples illustrate how fishing women provide emotional investment and emotional resources which their children are able to draw upon. Specifically, in this case, an awareness of the alternative career paths and the value of institutional cultural capital offered through school and education. Whilst authors such as Reay (2005) have noted the relationship of middle-class mothers' emotional capital to their children's educational attainment, our analysis suggests that in the fishing families, a more fundamental first step is in allowing a recognition that other career pathways are on offer and in advancing a subtle shift whereby the institutional cultural capital of education can be considered alongside the embodied and objectified cultural capital that fishing fathers (and likely their fathers before them) have prized so highly.

\section{Women, capital and change}

Whilst the previous sections have noted how women, explicitly and implicitly, reinforce gendered distinctions within 
fishing, it is crucial to recognise that they also exhibit their own autonomy, embody their own capital and seek to forge new gendered subjectivities:

Interviewer: 'Would you, for example, call yourself a wife of a fisherman?'

Woman: 'No. Years ago I suppose it would be different when the wife didn't work and they would live in a little cottage by the beach and you were all waiting for the men to come home... I suppose they used to call them fishermen's wives in them days but not now.[...Instead,] I wanted to work. If I want to change job I [would] just tell him $[\ldots]$ it is nice to have your independence isn't it?' (W-21 [Age, 60]).

In the extract above, woman 21 talks about how the label of 'fisherman's wife' depicts a traditional image which she cannot relate to, and in the interview, she draws on her own professional career to refute this label. Rather than being defined by the profession of her partner, she reports on her own professional identity and, similar to many other women interviewed, her own independent occupational identity or, in Bourdieusian terms, her own field-specific capital. Two broader observations emerge here for our understanding of gender dynamics in contemporary fishing communities: the fluidity of women's gender identities and performances and potential evidence of changes to the 'rules of the game' within the fishing field. As noted earlier in the paper, women may downplay their fishing contributions in simultaneously elevating their fishing partner's masculine subject position. When we dig deeper, however, we see how these women may gain a sense of self-identity from these other tasks that are ostensibly presented as 'subsidiary'. Whilst fishing men have often maintained a more monolithic gender subject position - commonly premised on notions of ruggedness, stoicism and technical competence-women in fishing families, in undertaking manifold roles both allied to and distinct from fishing, have forged multiple subject positions. It is in such examples that we may see changes to the 'rules of the game' within the fishing industry, which in turn may be bringing forward a disturbance to traditional gender relations. Whilst the gendered subject position taken by men, which we suggest has remained relatively continuous for many years, is born out a time when fishers were the sole breadwinner within families, the economic downturn of the industry over recent decades has meant very few are able to provide their family's only source of income from fishing. As a result, and noted in the extracts above, many women have independent employment outside of fishing. Women in the study worked in arenas such as cafes and restaurants, shops, health care and schools. The types of jobs women are employed in-associated with caring and the service sector - are significant in terms of being ones to which their cultural capital is malleable (after Huppatz 2009).

Whilst there remain performative and discursive ways in which fishing men's role remains of primary significance, the interviews suggested an increasing level of involvement and autonomy amongst fishing women:

Interviewer: 'If for example he buys new things for the boat, is that something that you are involved in?'

Woman: 'Well he wouldn't ask me. He would come in and say I have got to have this for the boat, I have got to have that. And then he would order it and I would say, how much does that cost? And he would probably tell me and I can look in the books.[...] I am not completely ignorant but if it has got to be bought it has got to be bought hasn't it? As long as he doesn't want a new boat [Laugh]. Not at his age. That will become completely different. No' (W-21 [Age, 60]).

Crucially in such extracts, it is revealed that whilst women may remain devoid of the 'masculine' cultural capital deemed necessary to make decisions on the type of fishing vessel purchased or everyday decisions about fishing techniques, their contribution of economic capital sees them exerting autonomy in, and in some cases resistance towards, these larger financial decisions. However, important within this - and something only revealed by the more in-depth ethnographic approach taken within this research - is that rarely do such examples of fishing autonomy become public. Such discussions take place within the context of the home, with fishing men appearing, to the outside world (and fishing community in particular), the primary decision maker. Important to contextualising these roles, however, is recognition of the changing nature of the fishing industry. The need to keep up-to-date records (such as catch records and boat insurances) and adhere to specific regulations means that bookkeeping is central to contemporary fishing, even at the small-scale considered here. Tracing this back through our discussion above, we can see how women become those most likely to undertake these roles-both through them being 'off sea' activities and through women having engaged with skills development through their past engagement with education as well as non-fishing employment.

\section{Conclusion}

Using the case of a smaller-scale fishery in the UK, this paper has used the idea of 'gendered capitals' to offer a fresh understanding of the gender(ed) spaces and subject positions within 
the industry. The paper has noted that particular fishing spaces and practices are gendered, and this limits the extent to which women are able to accrue and exhibit the capital which would allow them equal standing to their fishing men within the fishing occupation and community. The literal exclusion from masculine-coded fishing spaces is accompanied by a more discursive downplaying of women's positions in fishing which, simultaneously, elevates that of men. Significant to note, however, is that women are both central to supporting and reinforcing the development of these pre-existing capitals, as well as providing crucial capital in their own right. Whilst men's embodied cultural capital, and the objectified cultural capitals associated with resources such as boats and equipment, remain those most easily translated into symbolic capital and standing within the fishing community, women's allied roles are central to its continued development. Their less visible, but still crucial, roles in the home mean that their emotional capital - deployed in childcare, homemaking activities and sacrifice in terms of leisure activities and holidaysis central to providing a background which facilitates fishing men's work and ultimately the generation of economic capital. In this regard, our study offers a methodological blueprint for future research - with our approach of repeat interviews and observations highlighting that we need to observe the full range of spaces associated with fishing, including boats, homes, boat sheds etc.- - to fully appreciate the intricacies of the industry.

Far from seeing women as passive partners in small-scale fishing, our findings suggest that women are arguably central to its future. Structurally, as noted in previous research and reflecting a wider societal trend, women are more commonly pursuing their own forms of employment and providing economic capital which is not only central to the family, but to subsidising their partners' fishing, especially in times of low catch or adverse weather. Future research might usefully investigate these employment routes in more detail — extending on our tentative observation that women are arguably better placed, in terms of their own capitals, to find employment in the increasingly service sector-based economies of coastal regions such as those considered here. Alongside this, the changing nature of the fishing sector has meant that women's own skills are arguably central to its future development. Whilst activities such as bookkeeping remain largely hidden from public view, certainly in comparison to 'on boat' activities, they are increasingly central to the small-scale fishery. Finally, within the context of fishing family, our evidence suggests that women's emotional capital is not only central to supporting children - often alone, for long periods, as men go out to fish - but might also be responsible for offering up alternative career routes to their children, especially in light of the declining economic fortunes of the fishing industry in many parts of the world.
Acknowledgements The authors are grateful to the participants for volunteering their time. We also wish to thank the editors and reviewers for their constructive comments which helped to improve the paper.

Funding information The School of Environmental Sciences, University of Liverpool, funded the research. Support from the Economic and Social Research Council (ESRC) grant number ES/R00580X/1 to write this paper is gratefully acknowledged.

\section{Compliance with ethical standards}

Ethical approval was secured through the University of Liverpool.

Conflict of interest The authors declare that they have no conflict of interest.

Open Access This article is distributed under the terms of the Creative Commons Attribution 4.0 International License (http:// creativecommons.org/licenses/by/4.0/), which permits unrestricted use, distribution, and reproduction in any medium, provided you give appropriate credit to the original author(s) and the source, provide a link to the Creative Commons license, and indicate if changes were made.

\section{References}

Bourdieu, Pierre. 1984. Distinction: a social critique of the judgement of taste. London: Routledge.

Bourdieu, Pierre. 1986. The forms of capital. In Handbook of theory and research for the sociology of education, ed. J. Richardson, 241-258. New York: Greenwood press.

Bourdieu, Pierre. 1990. In other words: essays towards a reflexive sociology. Cambridge: Polity.

Britton, Easkey. 2012. Women as agents of wellbeing in Northern Ireland's fishing households. Maritime Studies 11 [online].

Cambiè, Giulia, Julia R. Pantin, Harriet Salmonsen, and Michel J. Kaiser. 2015. Economic performance and fishing strategies of the Welsh coastal fleet. Bangor: Fisheries and Conservation Science.

Chambers, Clare. 2005. Masculine domination, radical feminism and change. Fem Theory 6: 325-346.

Frangoudes, Katia. 2013. Women in fisheries: a European perspective. Brussels: European Parliament Policy Department B.

Gerrard, Siri. 2008. Quota policy and local fishing: gendered practices and perplexities. Maritime Studies 6: 53-75.

Gerrard, Siri. 2013. Mobilities, materialities, and masculinities: interconnected mobility practices in Norwegian coastal fisheries. Norsk Geografisk Tidsskrift - Norwegian Journal of Geography 67: 312-319.

Gersick, Kelin E., John A. Davis, Marion McCollom Hampton, and Ivan Lansberg. 1997. Generation to generation: life cycles of the family business. Boston: Harvard Business School Press.

Gustavsson, Madeleine. 2016. Examining the socio-cultural contexts of fishing lives on the Llyn Peninsula, UK. Unpublished $\mathrm{PhD}$ thesis. University of Liverpool.

Gustavsson, Madeleine, and Mark Riley. 2018. The fishing lifecourse: exploring the importance of social contexts, capitals and (more than) fishing identities. Sociol Rural 58 (3): 562-582.

Gustavsson, Madeleine, Mark Riley, Karyn Morrissey, and Andy Plater. 2017. Exploring the socio-cultural contexts of fishers 
and fishing: developing the concept of the 'good fisher'. $J$ Rural Stud 50: 104-116.

Gwynedd Council. 2014. Key statistics for Gwynnedd population density - wards. Bangor: Gwynned Council. https://www.gwynedd.llyw. cymru/en/Council/Documents\%2D\%2D-Council/Key-statisticsand-data/Land-area-and-population-density-in-Gwynedd.pdf Accessed 15 July 2016.

Gwynned Council. n.d. Gwynned Council Strategic Plan 2013-2017. Bangor: Gwynned Council. https://www.gwynedd.llyw.cymru/en/ Council/Documents\%2D\%2D-Council/Performance-and-spending/ Strategic-plan-201314.pdf Accessed 27 July 2018.

Huppatz, Kate. 2009. Reworking Bourdieu's 'capital': feminine and female capitals in the field of paid caring work. Sociology 43: 45-66.

Huppatz, Kate, and Susan Goodwin. 2013. Masculinised jobs, feminised jobs and men's 'gender capital' experiences: Understanding occupational segregation in Australia. J Sociol 49: 291-308.

Illouz, Eva. 1997. Who will care for the caretaker's daughter? Towards a sociology of happiness in the era of reflexive modernity. Theory, Culture \& Society 14: 31-66.

Jones, Rhys, and Carwyn Fowler. 2007. Where is Wales? Narrating the territories and borders of the Welsh linguistic nation. Reg Stud 41: 89-101.

Kilpatrick, Sue, Tanya J. King, and Karen Willis. 2015. Not just a fisherman's wife: women's contribution to health and wellbeing in commercial fishing. Aust J Rural Health 23: 62-66.

Kleiber, Danika, Leila M. Harris, and Amanda C.J. Vincent. 2015. Gender and small-scale fisheries: a case for counting women and beyond. Fish Fish 16: 547-562.

Little, Jo, and Ruth Panelli. 2003. Gender research in rural geography. Gender, Place and Culture 10: 281-289.

Marine Management Organisation. 2017. UK Sea Fisheries Statistics 2016. Newport: National Statistics.

McCall, Leslie. 1992. Does gender fit? Bourdieu, feminism, and conceptions of social order. Theory Soc 21: 837-867.

McNay, Lois. 2000. Gender and agency: reconfiguring the subject in feminist and social theory. Cambridge: Polity.

Munk-Madsen, Eva. 1996. From common property to all-male property. In Proceedings of the workshop: social implications of quota systems. Vestman Island, Iceland May 1996 Nordic Council of Ministers, Copenhagen.

Munk-Madsen, Eva. 2000. Wife the deckhand, husband the skipper. Women's Stud Int Forum 23: 333-342.
Nadel-Klein, Jane and Dona Lee Davis, ed. 1988. To work and to weep: women in fishing economies. St. John's Newfoundland, Canada: instiute of social and economic research, Memorial Univeristy of Newfoundland.

National statistics for Wales. 2013. Annual survey of hours and earnings for Wales, 2012. Statistical Bulletin. Cardiff: Analytical and Knowledge Services, Welsh government. https:/gov.wales/docs/ statistics/2013/130110sb12013en.pdf Accessed 28 July 2018.

Neis, Barbara, Siri Gerrard, and Nicole G. Power. 2013. Women and children first: the gendered and generational social-ecology of smaller-scale fisheries in Newfoundland and Labrador and Northern Norway. Ecol Soc 64 (online): 18.

Porter, Marilyn. 2012. Why the coast matters for women: a feminist approach to research on fishing communities. Asian Fisheries Science 25: 59-73.

Power, Nicole G. 2005. What do they call a fisherman? Men, gender, and restructuring in the Newfoundland fishery. St. John's: Institue of social and economic research, Memorial Univeristy.

Power, Nicole G. 2012. Is there a place for youth in fisheries communities? a multiple perspectives discussion Workshop Synthesis Report: Community-University Research for Recovery Alliance (CURRA). St John's: Memorial University.

Reay, Diane. 2005. Gendering Bourdieu's concepts of capitals? Emotional capital, women and social class. The Sociological Review 52: 57-74.

Reismann, Catherine Kohler. 2008. Narrative methods for the human sciences. Thousand oaks: SAGE publications.

Skaptadottir, Unnur D. 1996. Gender construction and diversity in Icelandic fishing communities. Anthropologica 38: 271-287.

Waitt, Gordon, and Kate Hartig. 2005. All at sea. Rethinking fishers' identities in Australia. Gender, Place \& Culture 13: 403-418.

White, Carole Sandrine. 2015. Getting into fishing: recruitment and social resilience in North Norfolk's 'cromer crab' fishery, UK. Sociol Rural 55: 291-308.

Yodanis, Carrie L. 2000. Constructing gender and occupational segregation: a study of women and work in fishing communities. Qual Sociol 23: 267-290.

Zhao, Minghua, Marilyn Tyzack, Rodney Anderson, and Estera Onoakpovike. 2013. Women as visible and invisible workers in fisheries: a case study of Northern England. Mar Policy 37: 69-76. 